\title{
Glottis Closure for Intractable Aspiration Patient with Tracheal Defect and Tracheoesophageal Fistula
}

\author{
Hyun Woo Park ${ }^{1}$, Jin Pyeong Kim ${ }^{1,2}$, Jung Je Park ${ }^{1,2}$ and Seung Hoon Woo ${ }^{1,2}$ \\ ${ }^{1}$ Department of Otolaryngology, ${ }^{2}$ Institute of Health Sciences, Gyeongsang National University College of Medicine, Jinju, Korea
}

\section{광범위한 기관결손과 기관식도누공을 동반한 만성 흡인환자의 성문폐쇄술}

박현우 ${ }^{1} \cdot$ 김진평 ${ }^{1,2} \cdot$ 박정제 $^{1,2} \cdot$ 우승훈 ${ }^{1,2}$

경상대학교 의과대학 이비인후과학교실, ${ }^{1}$ 건강과학연구원 ${ }^{2}$

\author{
Received June 9, 2011 \\ Revised July 12,201 \\ Accepted July 26, 2011 \\ Address for correspondence \\ Seung Hoon Woo, MD \\ Departments of Otolaryngology, \\ Institute of Health Sciences, \\ Gyeongsang National University \\ College of Medicine, \\ 79 Gangnam-ro, Jinju 660-702, \\ Korea \\ Tel $+82-55-750-8173$ \\ Fax $+82-55-759-0613$ \\ E-mail lesaby@hanmail.net
}

Many surgical procedures have been established to treat swallowing disorders with aspiration. These operations allow restoration of respiration and deglutition without aspiration. Many surgical procedures have been established to treat intractable aspiration. It is important to evaluate the state of the patient and swallowing disorder; surgical procedures can then be selected according to the pathophysiology. We describe a patient who underwent a glottic closure for intractable aspiration following a failure of tracheal end to end anastomosis. Glottic closure is relatively easy to perform and potentially reversible. It was the best choice of treatment for large defect of trachea with intractable aspiration.

Korean J Otorhinolaryngol-Head Neck Surg 2012;55:42-5

Key Words Trachea $\cdot$ Sutures $\cdot$ Glottis $\cdot$ Anastomosis $\cdot$ Aspiration.

\section{서 론}

기관식도루는 기관과 식도 사이의 비정상적인 샛길의 형성 을 말하는데 염증 또는 장기적인 기관삽관이나 기관절개술, 외 상, 종양 등에 의해 후천적으로 발생할 수 있으며 선천적 기형 의 일부로도 발생 가능하다. 기관식도 병변의 수술적 치료 중 의 하나가 병변의 절제 후 단단문합술이지만 이는 수술 자체 의 어려움과 술 후 일정 기간 동안 자세의 유지 및 수술 후 재 협착 등 합병증의 빈도가 높다. 그리고 단단문합술의 경우 기 관결손의 크기가 크면 시행할 수 없다는 단점이 있다.,2)

기관식도루로 인해 광범위 기관결손이 있는 경우 인후두의 타액은 결손부위로 흘러들어가 결손부위의 염증조절의 어려 움과 점차로 커지는 결손, 그리고 이로 인해 무명동맥(innominate artery) 등의 침식을 유발할 수 있다. 따라서 타액이 병변 부위로 유입되는 것을 막는 것이 치료의 시작이 된다.

저자들은 기관식도루를 가진 환자에서 기관단단문합술과
기관식도루의 일차 봉합 실패 후 인후두에서 내려오는 타액 등에 의해 수술부위 염증 조절이 안되는 환자에 있어 후두현 수 현미경하 후두봉합을 통한 성문폐쇄술과 식도 봉합을 시 행하여 문헌고찰과 함께 보고하고자 한다.

\section{증 겨}

47세 여자 환자가 광범위 기관결손 및 흡인으로 흥부외과 로부터 의뢰되었다.

환자는 4년 전 당뇨병을 진단받았으나 약물복용은 하지 않 았고 내원 5일 전부터 발생한 발열 및 의식저하로 응급실에 내원하였다. 환자에게 기관내 삽관을 시행하였으며 전신 이학 적 검사상 환자의 회음부위에서 $1.5 \mathrm{~cm}$ 크기의 가피가 형성되 어 있는 것을 확인하였고 쯔쯔가무시병 진단 하에 환자에게 doxycycline 치료를 시작하였다. 이후 장기화된 기관내 삽관 으로 환자는 기관절개술을 시행하였으며 경과관찰 중 기관 
절개술 부위의 감염 및 염증으로 기관의 결손 및 기관식도 누 공이 형성되었다. 흥부외과에서 기관식도 누공을 제거하고 식도의 일차 봉합술 및 기관의 염증부위를 제거한 후 단단 문합술을 시행하였다. 그러나 기관단단문합술 부위의 염증 조 절의 실패로 단단문합술이 실패하였고 이후 $7 \mathrm{~cm}$ 정도의 광범 위 기관결손을 보이게 되었다. 추가로 일차 봉합하였던 식도 도 염증 반응에 의해 봉합 부위가 풀리면서 인후두로부터 내 려오는 타액이 지속적으로 기관으로 흡인되는 상태였으며 주 위의 조직들도 타액에 의해 점차로 염증이 진행되어 전경부에 상당한 크기의 조직 결손이 보이는 상황이었다. 이전의 기관단 단문합술과 염증으로 인해 괴사된 기관의 결손은 너무 커서 기관단단문합술의 재시행은 불가능해 보였다. 후두 검사상 양 측 성대는 방정중(para-median) 부위에 고정되어 있었다. 따 라서 우선적으로 타액이 마비된 성대와 식도의 누공에서 기관 과 경부로 흡인되는 것을 막고 새로운 기도(airway)를 만들어 야 하는 상황이었다.

수술 전 시행한 3차원 두경부 전산화단층촬영상 기관은 윤 상연골 바로 아래부터 약 $7 \mathrm{~cm}$ 의 기관결손 및 광범위한 연부
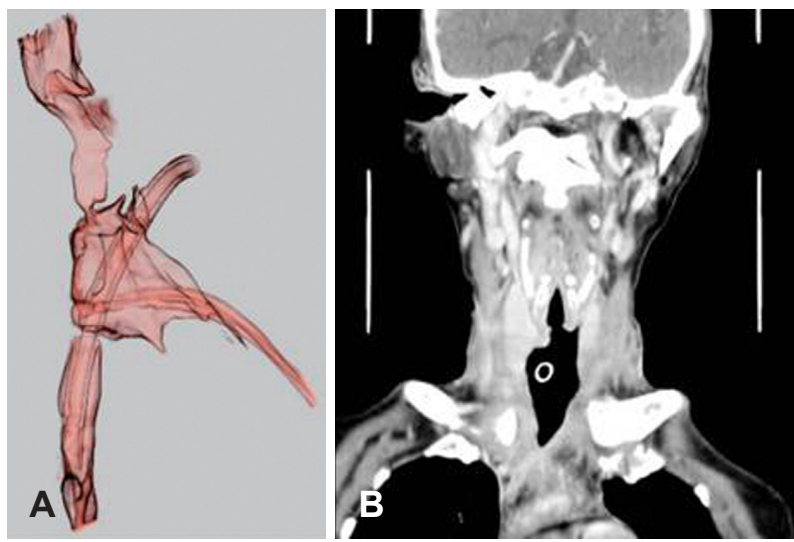

Fig. 1. Preoperative computed tomography image of patient with $7 \mathrm{~cm}$ sized tracheal defect under cricoid cartilage. Airway reconstruction image (A). Coronal image (B).
조직 결손이 있었다(Fig. 1). 보전적 치료가 불가능할 것으로 사료되어 상기환자에게 수술적 치료를 계획하였다. 수술의 1 차 목적은 인후두로부터의 타액이 기관과 경부로 들어가지 않 게 하는 것이었으며, 이후 가능할 경우 기관의 재건을 고려하는 것이었다. 우선 식도 봉합술과 경부 조직 결손 부위를 통해 바
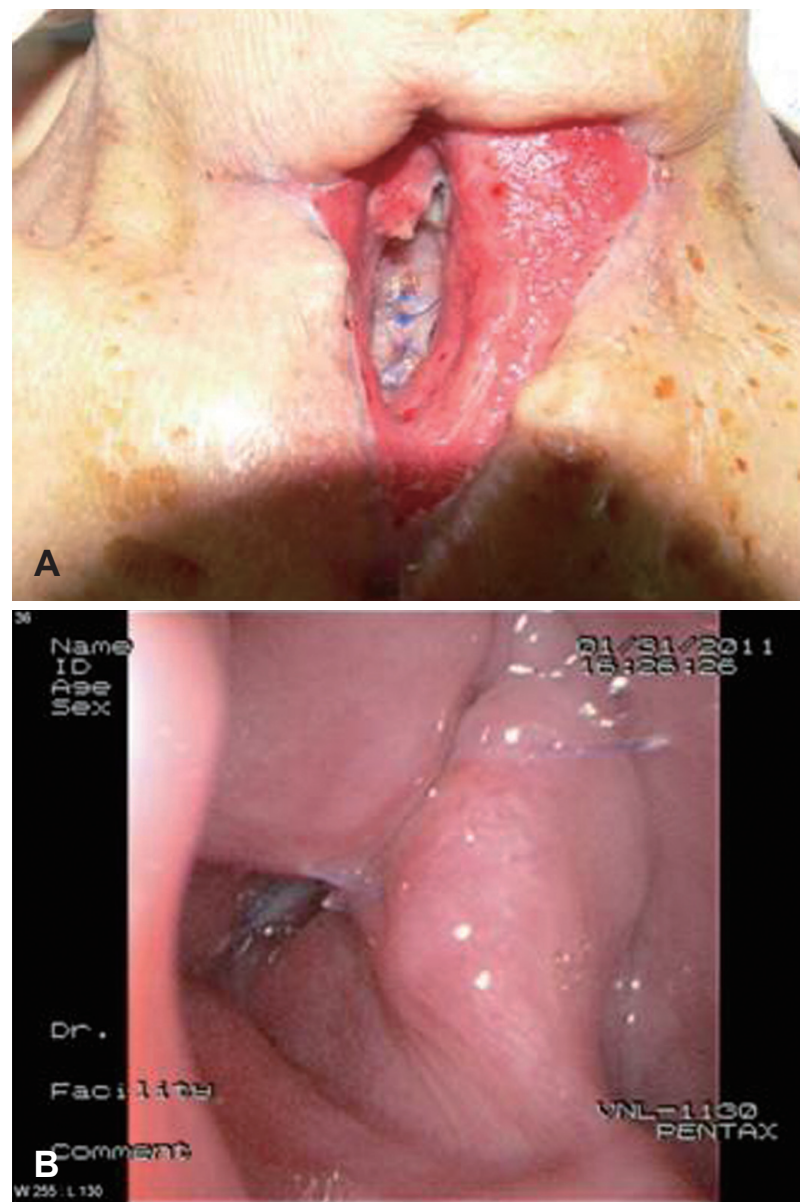

Fig. 3. Postoperative follow up image. Well healed esophageal fistula site (A). Well healed laryngeal closure site without glottic dehiscence $(B)$.
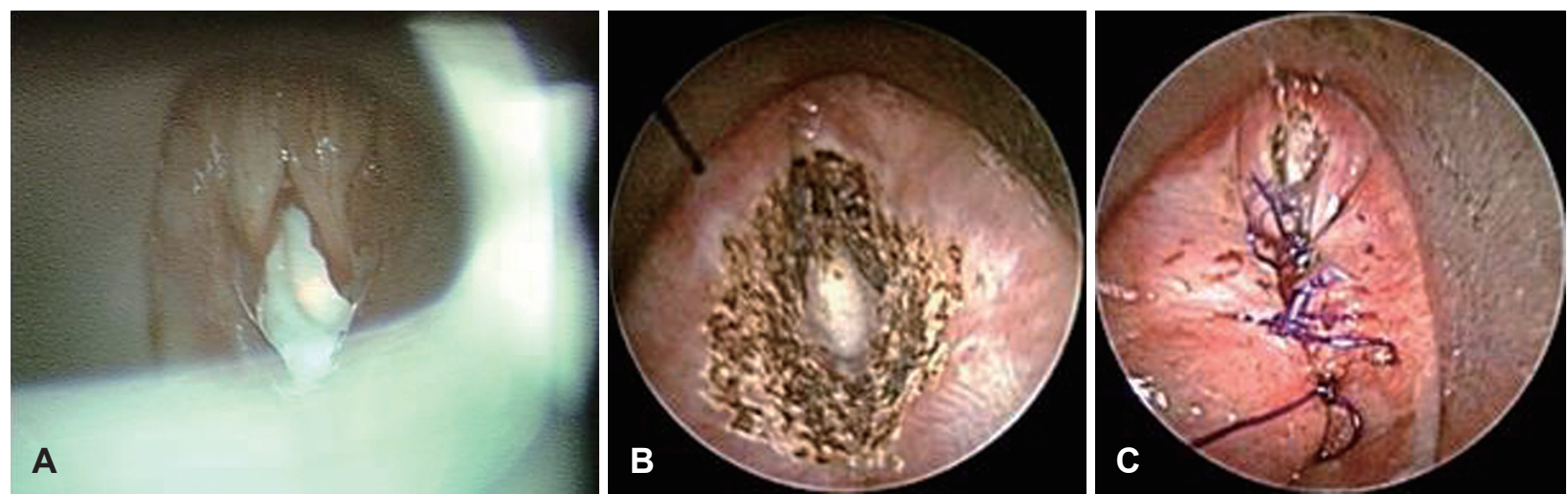

Fig. 2. Intraoperatve suspension laryngoscope image. Initial image before procedure (A). Image after laser cauterization of glottis mucosal surface (B). Image after suture bilateral true vocal cord, false vocal cord, arytenoids cartilage (C). 
로 보이는 윤상연골의 내측 연골막을 봉합하는 수술법을 계 획하였다. 수술소견상 식도 누공은 약 $3 \mathrm{~cm}$ 크기로 염증 제거 후 봉합이 가능하였다(Fig. 3A). 기관은 윤상연골 직하방으로 부터 약 $7 \mathrm{~cm}$ 이상의 결손이 보였다. 기관의 결손은 염증조직 의 제거 후 더 커졌으며 이전의 단단문합술을 시행하면서 이미 흥곽내 기관은 최대한 이완되어 당겨진 상태여서 단단문합 술의 재시행은 불가능하였다. 상부로 윤상연골과 갑상연골 만 남아있는 상태였으므로 기관식도 우회술(tracheoesophageal diversion)이나 후두기관 분리술(laryngo-tracheal seperation)을 시행할 수는 없었다. 윤상연골 내측 연골막을 박리 하여 봉합하는 방법을 고려하였으나 만성적인 염증으로 인해 윤상연골막은 정상적인 기능을 수행할 수 없는 상태를 보이고 있었다. 따라서 성문 하부에서 시행하려던 수술법을 포기하고 후두개를 이용한 성문상부폐쇄술(epiglottic flap closure)나 후두폐쇄술(glottic closure)로 전환하였다.

환자에게 경성후두경(suspension laryngoscope)을 삽입하 고 후두를 노출시켰다. 후두는 방정중 위치에 고정되어 있었 으며 육안적인 소견으로는 약간의 염증과 부종 외에는 특이소 견이 보이지 않았다(Fig. 2A). 진성대와 가성대를 확인한 후 봉합의 안전성을 위해 $\mathrm{CO}_{2}$ 레이저를 사용하여 성대와 피열연 골의 점막표면을 소작하였다(Fig. 2B). 이후 경성후두경과 현 미경을 통해 4-0 PDS를 미세봉합겸자(microscopic needle holder)를 사용하여 양쪽의 피열연골을 관통하여 봉합하였 다. 이후 진성대를 봉합하고 안전성을 위해 주위의 가성대도 봉합하였다(Fig. 2 C). 이후 타액의 누출이 없는 것을 확인하 고 수술을 마쳤다.

수술 후 6개월이 지난 현재까지 성문폐쇄술 부위의 봉합은 잘 유지되고 있으며 타액의 유출도 관찰되지 않았다. 그리고 식도의 누공도 닫힌 상태로 기관결손 부위의 염증도 조절되 었으며 현재 경과관찰 중이다(Fig. 3). 추후 결손된 기관 부위 의 재건과 향후 치료 계획에 대해서는 흥부외과와 협의중이다.

\section{고 찰}

기관절제술 및 단단문합술은 기관내 삽관, 원발성 종양 등 에 의한 기관 협착, 또는 기관지 결핵, 외상, 감염 등에서 시행 된다. 기관 협착의 경우에서는 기관절제 및 단단문합술의 시 행 이전에 내시경을 통한 기관내 수술, 기관절제 및 재건술, 기 관성형술 등이 시행가능하지만 기관절제 및 단단문합술이 해부학적 또는 기능적으로 정상적인 기도를 확보한다는 점에 서 가장 이상적인 방법으로 알려져 있으며 기관의 혈액 공급과 기관의 이완술에 대한 연구로 발전을 거듭해왔다. ${ }^{3)}$ 이러한 연 구의 결과 오늘날 기관 전장의 $1 / 3$ 까지 절제가 가능하다. ${ }^{3,4}$ 하
지만 병변의 위치와 길이에 따른 수술의 한계와 수술부위의 긴장으로 인한 문합부위의 봉합부전, 수술 후 재협착의 발생 등의 합병증은 치명적인 결과를 초래할 수 있다. 본 증례와 같 이 단단문합술의 실패 이후 광범위한 기관결손이 나타나고 식 도 누공까지 같이 있어 타액이 지속적으로 흡인된다면 환자의 생명까지도 위험할 수 있는 상황에 직면하게 된다.

흡인의 치료는 자세교정술, 감각증대술, 연하요법 및 음식물 성상변화, 구강 내 보형물 등의 보존적인 치료를 시도해 볼 수 있지만 본 증례와 같이 흡인의 조절에 실패하고 흡인으로 인 해 추가적인 합병증이 발생할 경우 수술적인 치료가 필요하다.5) 수술적인 치료는 만성 흡인의 원인에 따라 다양한 방법이 보 고되고 있다. 이 중 본 증례와 같이 광범위한 기관결손이 있을 경우 음식물과 공기의 통로를 분리하는 방법 등을 고려해야 하는데, 후두개를 피판으로 이용하여 봉합하거나 이것을 변 형시킨 후두성형술 등의 성문상부 봉합법, 성대를 봉합하는 성문폐쇄법이 실시될 수 있다. ${ }^{67}$ 성문하 봉합법으로 기관식도 우회술(tracheoesophageal diversion)이나 후두기관 분리술 (laryngo-tracheal seperation) 등이 실시될 수 있으며 이러한 경우 모두 가역적 방법이고 연하장애 및 흡인의 위험성이 없 어졌을 때 재건이 가능하다. ${ }^{8-10)}$ 흡인을 방지하기 위해 사용할 수 있는 마지막 방법으로 비가역적이지만 후두적출술(total laryngectomy)도 고려할 수 있다. ${ }^{11)}$

본 증례에 사용된 성문폐쇄법(glottic closure)은 1952년 Montgomery ${ }^{6}$ 에 의해 처음 소개되었으며 이후 Sasaki 등에 의해 변형되어 사용되고 있다. 이 방법은 음성은 소실되나 높 은 수술 성공률을 보인다. 그러나 전경부를 통한 갑상연골 정 중절개시행 후 직접 봉합을 하는 방법이므로 환자에 따라서 적용이 어려운 경우도 있다. 최근의 기술과 미세수술법의 발 달로 인해 성문폐쇄법을 갑상연골 정중절개 없이도 현수 현 미경하에서 시행 가능하게 되었다. ${ }^{2)}$ 문헌상 현수 현미경하에 서 시행 가능한 또 다른 성문 상부폐쇄술의 경우 후두개 피판 폐쇄술(epiglottic flap closure)이 보고되고 있으나 후두개를 사용할 경우 후두개 자체의 강한 탄력과 후두개의 점막의 괴 사 등이 우려되며 더구나 후두경을 통한 후두개 피판의 봉합 이 어려워 후두를 직접 봉합하는 방법을 적용하게 되었다. ${ }^{7)}$

본 증례에서 환자는 기관식도누공으로 기관단단문합술을 시행받고 봉합 부위의 염증으로 인해 광범위한 기관결손과 치명적인 흡인이 발생한 경우로 보전적인 치료로 호전의 가능 성이 없어 수술적인 처치로 음식물과 공기의 통로를 분리시켜 주는 수술이 필요하였다. 여러 수술방법 중 후두경을 이용한 성문폐쇄법을 적용하게 된 이유는 광범위한 염증으로 인해 상 문하부 봉합법들인 윤상연골 점막봉합법과 윤상연골 절제 술 등을 사용할 수 없었고, 식도의 누공으로 인해 식도 자체에 
또 다른 염증을 유발할 수 있는 후두전절제술(total laryngectomy)의 사용도 용이하지 않았다. 따라서 광범위 염증부분을 피해 안전하고 절개 부위를 최소화 할 수 있는 방법을 고민하 였고 결과적으로 현수 후두경하 후두폐쇄술을 시행하게 되 었다.

이 수술의 합병증으로는 시술 후 피열간극 부위 접합 부위 가 벌어지는 합병증이 발생할 수 있으나, 본 증례에서는 연골 부위의 점막을 레이저를 이용해 제거하고 봉합시 피열연골을 봉합사로 관통하여 봉합하였으므로 이와 같은 합병증을 예 방할 수 있었다. ${ }^{6}$

결론적으로 후두문합을 통한 후두기관 분리술은 수술 후 발성이 불가능하다는 단점이 있으나 심경부 감염 환자에서 기 관식도의 결손이 있을 때 타액으로 인한 수술부위 염증조절 의 어려움에 있어서 기관단단문합술이 불가능한 경우, 그리 고 이미 기관단단문합술을 한 차례 이상 실패하여 재시행이 불가능한 경우 효과적인 방법으로 사료된다. 특히 환자의 기 저질환 및 전신 상태가 좋지 않을 경우 시행 가능한 비교적 간단한 수술이며 술 후 경부 염증의 조절뿐만 아니라 흡인성 폐렴 등 하부기관염증의 감소, 재원기간의 단축, 보호자의 부 담의 감소, 안전한 경구식이가 가능하다는 여러가지 장점이 있을 수 있다. ${ }^{10,12)}$

저자는 후두현수 현미경을 통한 후두미세수술법으로 후 두문합술을 시행하여 단단문합술이 불가능한 기관결손 및 식도누공을 동반한 경부 염증환자를 치험한 증례를 참고문
헌과 함께 보고하고자 한다.

\section{REFERENCES}

1) Shen KR, Allen MS, Cassivi SD, Nichols FC 3rd, Wigle DA, Harmsen WS, et al. Surgical management of acquired nonmalignant tracheoesophageal and bronchoesophageal fistulae. Ann Thorac Surg 2010;90(3):914-8; discussion 919.

2) Bayrak Y, Tanju S, Suoglu Y, Toker A. Treatment of a benign tracheoesophageal fistula in a ventilator dependent quadriplegic patient. Thorac Cardiovasc Surg 2006;54(8):554-5.

3) Yu YG, Park SI, Park SI, Kim YH, Park KS, Kim DK, et al. Result of tracheal resection and end-to-end anastomosis. Korean J Thorac Cardiovasc Surg 2003;36(4):267-72.

4) Ferguson DJ, Wild JJ, Wangensteen $\mathrm{OH}$. Experimental resection of the trachea. Surgery 1950;28(3):597-619.

5) Eisele DW. Surgical approaches to aspiration. Dysphagia 1991;6(2): 71-8.

6) Montgomery WW. Surgery to prevent aspiration. Arch Otolaryngol 1975;101(11):679-82.

7) Remacle M, Marza L, Lawson G. A new epiglottoplasty procedure for the treatment of intractable aspiration. Eur Arch Otorhinolaryngol 1998;255(2):64-7.

8) Lindeman RC. Diverting the paralyzed larynx: a reversible procedure for intractable aspiration. Laryngoscope 1975;85(1):157-80.

9) Yarington CT, Sutton D. Clinical experience with the tracheoesophageal anastomosis for intractable aspiration. Ann Otol Rhinol Laryngol 1976;85(5 Pt.1):609-12.

10) Eisele DW, Yarington CT Jr, Lindeman RC, Larrabee WF Jr. The tracheoesophageal diversion and laryngotracheal separation procedures for treatment of intractable aspiration. Am J Surg 1989;157(2):230-6.

11) Cannon CR, McLean WC. Laryngectomy for chronic aspiration. Am J Otolaryngol 1982;3(2):145-9.

12) Eibling DE, Snyderman CH, Eibling C. Laryngotracheal separation for intractable aspiration: a retrospective review of 34 patients. Laryngoscope 1995;105(1):83-5. 